also form a potential feedback loop for assessing the effectiveness of the programmes.

We thank the Northern region educational supervisors, clinical tutors, and postgraduate centre managers.

Contributors: JS designed the study protocol, collected and analysed the data, and participated in writing the paper. CO' $\mathrm{H}$, $\mathrm{PH}$, and JAS conceived the study, developed the study design, and participated in writing the paper. JRB and SS guided the study design and participated in writing the paper. JS and CO'Halloran will act as guarantors for the paper.

Funding: Medical and Dental Education Levy and the Northumberland Health Authority.

Competing interests: SJS was chairman of the Local Medical Workforce Advisory Group while the study was being conducted.

1 General Medical Council. Tomorrow's doctors. London: GMC, 1993.

2 General Medical Council. The new doctor London: GMC, 1997.

3 Dowling S, Barrett S. Doctors in the making: the experience of the pre-registration year. Bristol: Saus, 1991.

4 Leslie PJ, Williams JA, McKenna C, Smith G, Heading RC. Hours, volume and type of work of pre-registration house officers. BMJ 1990;300:103841.

5 Turnbull NA, Miles NA, Gallen IW. Junior doctors' on-call activities: differences in workload and work patterns among grades. BMJ differences in work

6 Dent THS, Gilliard JH, Aarons EJ, Smyth-Pigott PJ. Variations in clinical experience of pre-registration house officers: the effect of London. Health Trends 1995;27:22-6.

7 British Medical Association. BMA cohort study of 1995 medical graduates: second report. The pre-registration year. London: BMA, 1997.

8 McKee M, Black N. Junior doctors' work at night: What is done and how much is appropriate? J Public Health Med 1993;15:16-24.

9 Jones J, Hunter D. Consensus methods for medical and health services research. BMJ 1995;311:376-80.

10 Duffield C. The Delphi technique. Aust J Adv Nurs 1988;6:41-5.

11 Williams PL, Webb C. The Delphi technique: a methodological discussion. J Adv Nurs 1994;19:180-6.

12 Conference of Postgraduate Medical Deans and Directors of Postgraduate Medical Education of Universities in the UK. The pre-registration house officer experience: implementing change. London: COPMED, 1994.

13 Gillard JH, Dent THS, Aarons EJ, Smyth-Pigott PJ, Nicholls MWN. Pre-registration house officers in eight English regions: survey quality of training. BMJ 1993;307:1180-4

14 Mitchell IA, Teale GR. The practical house officer. Oxford: Blackwell Scientific, 1992.

15 Calman KC, Donaldson M. The pre-registration house officer year: a critical incident study. Med Educ 1991;25:51-9.

16 Dent THS, Gilliard JH, Aarons EJ, Crimlisk HL, Smyth-Pigott PJ Pre-registration house officers in the 4 Thames regions. 1: survey of education and workload. BMJ 1990;300:713-6.

17 Firth-Cozens J, Morrison LA. Sources of stress and ways of coping in junior house officers. Stress Med 1989;5:121-6.

18 Elizabeth JE, Hughes S. An assessment of the pre-registration year experience. $B M J$ 1986;293:1559.

19 Dornbusch SM, Scott WR. Evaluation and the exercise of authority. San Francisco: Jossey-Bass, 1975:71.

(Accepted 12 May 1999)

\title{
Changes in risk of hospital readmission among asthmatic children in Denmark, 1978-93
}

\author{
Hans Bisgaard, Henrik Møller
}

The management of asthma in children has changed over the two most recent decades, with increasing emphasis on early anti-inflammatory treatment and complete disease control with inhaled steroids. ${ }^{12}$ We estimated the changes in hospital readmission rates for asthma in children in Denmark in 1978-93 with a view to evaluating concomitant changes in disease control.

\section{Methods and results}

Data on hospital admissions and subsequent readmissions with asthma in children aged 5-14 at first admission were obtained from the Danish National Board of Health for the period 1978-93. Readmission was defined as any subsequent admission related to asthma that was separated by 12 months or more from the first admission.

The age standardised incidence of admission to hospital for asthma was calculated by dividing the number of first admissions to hospital for asthma by the corresponding population group in the Danish population. Sequences in which a person was discharged from hospital and again admitted on the same day (as is often the case when a patient is moved from one department to another) were combined into a single admission. Age standardised rates were calculated by giving equal weights to different age groups and to the two sexes. Relative risks of readmission in different groups of patients were estimated with Cox proportional hazards regression, account being taken of sex, diagnosis at first admission, age at first admission, and period in which the first admission occurred.

The incidence of admission to hospital for asthma over the period studied was constant at roughly 1 per 1000 children per year (table). The proportional hazards regression analysis showed that the relative risk of readmission for asthma decreased gradually; in children who were first admitted to hospital for asthma in 1990-3 the estimate was 0.50, compared with 1.00 in children first admitted in 1978-81 (table). Furthermore, the mean number of days per admission decreased over the study period.

\section{Comment}

The risk of readmission for asthma in Danish children fell by half during the period from 1978 to 1993 ; the incidence of admission for asthma in these children was constant in this period.

The frequency of hospital admissions may be affected by at least three factors, all expected to favour

Incidence of admission to hospital for asthma, relative risk of readmission, and average number of days in hospital per admission among asthmatic children during 1978-93

\begin{tabular}{|c|c|c|c|c|c|}
\hline \multirow[b]{2}{*}{ Period } & \multirow{2}{*}{$\begin{array}{c}\text { Incidence of } \\
\text { first } \\
\text { admissions } \\
\text { (per 1000) }\end{array}$} & \multirow[b]{2}{*}{$\begin{array}{l}\text { Relative risk of } \\
\text { readmission }(95 \% \mathrm{CI})\end{array}$} & \multirow[b]{2}{*}{$P$ value } & \multicolumn{2}{|c|}{$\begin{array}{l}\text { Average No of days in hospita } \\
\text { per admission }\end{array}$} \\
\hline & & & & $\begin{array}{c}\text { First } \\
\text { admission }\end{array}$ & Readmissions \\
\hline 1978-81 & 0.93 & 1 & & 5.1 & 5.9 \\
\hline $1982-5$ & 1.10 & 0.75 (0.66 to 0.85$)$ & $<0.001$ & 3.5 & 5.0 \\
\hline 1986-9 & 1.14 & 0.64 (0.53 to 0.74$)$ & $<0.001$ & 3.5 & 4.6 \\
\hline 1990-3 & 1.09 & 0.50 (0.32 to 0.68$)$ & $<0.001$ & 3.2 & 3.7 \\
\hline
\end{tabular}

Department of Paediatrics, Rigshospitalet, National University Hospital, DK-2100 Copenhagen, Denmark

Hans Bisgaard, professor of paediatrics

Centre for Research in Health and Social Statistics, Danish National Research Foundation, DK-2100 Copenhagen Henrik Møller, head

Correspondence to: Professor Bisgaard Bisgaard@RH.DK

BMJ 1999;319:229-30 
an upward trend: the underlying incidence of asthma seems to have been increasing over recent decades in children in industrialised countries ${ }^{34}$; awareness of asthma is believed to have increased during the observation period; and a labelling shift from bronchitis to asthma has probably occurred during this period.

Because an increased incidence of new admissions to hospital for asthma was not observed, other factors must have had a moderating influence on the risk of admission. The factors favouring an increased incidence of asthma may mainly contribute mild cases of asthma, which would add little to the risk of admission to hospital and readmission. This is probably not, however, a major factor, since the relative contribution of short admissions was unchanged throughout the period. The reduced risk of readmission over the study period therefore suggests that the treatment of chronic asthma has improved. The reduced length of stay in hospital for both first admissions and readmissions substantiates this interpretation of our data.
In conclusion, these data provide evidence suggesting that the management of asthma in Danish children has improved, leading to less frequent readmission and to shorter stays in hospital.

Contributors: $\mathrm{HB}$ and $\mathrm{HM}$ contributed jointly to the design, analysis, interpretation, and reporting of this study and are both guarantors for the paper.

Competing interests: $\mathrm{HB}$ has been funded by major pharmaceutical companies producing antiasthma drugs, including GlaxoWellcome, Astra, Merck, and Novartis.

1 Warner JO, Naspitz CK. Third international pediatric consensus statement on the management of childhood asthma. International Pediatric Asthma Consensus Group. Pediatr Pulmonol 1998;25:1-17.

2 Bisgaard H. Use of inhaled corticosteroids in pediatric asthma. Pediatr Pulmonol 1997:15:27-33.

3 Ninan TK, Russell G. Respiratory symptoms and atopy in Aberdeen schoolchildren: evidence from two surveys 25 years apart. BMJ 1992;304:873-5.

4 Magnus P, Jaakkola JJK. Secular trend in the occurrence of asthma among children and young adults: critical appraisal of repeated cross sectional surveys. BMJ 1997;314:1795-9.

(Accepted 9 February 1999)

\title{
Outcome and use of health services four years after admission for acute myocardial infarction: case record follow up study
}

\author{
Martin Melville, Nigel Brown, David Gray, Tracey Young, John Hampton
}

Department of Cardiovascular Medicine,

University Hospital, Nottingham NG7 2UH

Martin Melville, research assistant Nigel Brown, specialist registrar in cardiology

David Gray, reader in medicine John Hampton, professor of cardiology

British Heart

Foundation

Cardiovascular

Statistics Unit,

Department of

Mathematics,

University of

Nottingham,

Nottingham

NG7 2RH

Tracey Young,

research assistant

Correspondence to: M Melville

martin.melville@

nottingham.ac.uk

BMJ 1999;319:230-1
Acute myocardial infarction affects around 250000 people each year in the United Kingdom. To our knowledge, medium term outcome and use of resources, other than revascularisation rates, ${ }^{1}$ have not been reported in a non-selected population.

\section{Subjects, methods, and results}

All patients resident in Nottingham Health District who had been admitted in 1992 for acute myocardial infarction to either of Nottingham's two hospitals were identified from the Nottingham heart attack register. ${ }^{2}$ We reviewed all hospital and general practitioner case notes for investigations, interventions, readmissions, clinic visits, and symptoms up to August 1996. Data on deaths were obtained from the Office for National Statistics.

Overall, 900 patients were admitted for myocardial infarction (mean age 66.6 years; 561 men). Data extraction was completed in 899 (99.9\%). The table shows the outcomes in the 695 patients who were discharged alive.

In all, 537 patients received a clinic appointment on discharge (eight did not attend and seven others had died). The remaining 158 did not receive follow up-medical records did not indicate why.

Only 126 (24\%) patients who were followed up had had a previous myocardial infarction compared with $66(42 \%)$ of those who were not $\left(\chi^{2}=20.47, \mathrm{P}<0.001\right)$. The two groups did not differ in size of infarct (as measured by rise in creatine kinase concentrations $\left(\chi^{2}=1.51, \quad \mathrm{P}=0.219\right)$, location of infarct $\left(\chi^{2}=0.72\right.$, $\mathrm{P}=0.399)$, or Killip score at hospital presentation $\left.\left(\chi^{2}=2.27, \mathrm{P}=0.132\right)\right)$. Patients without follow up were, however, less likely to have received thrombolysis $\left(\chi^{2}=25.01, \mathrm{P}<0.001\right)$ and to have been under the care of a cardiologist; 142 of the $519(27 \%)$ patients managed by a physician and 16 of the $176(9 \%)$ managed by a cardiologist were not followed up $\left(\chi^{2}=24.97\right.$; $\mathrm{P}<0.001)$. These patients were no more likely to require readmission in the four years after infarction, but after adjustment for age, sex, and previous infarction $79(50 \%)$ had died compared with $130(24 \%)$ $(\mathrm{z}=3.44, \mathrm{P}=0.001)$. There were no differences in the proportion of deaths from coronary heart disease in the two groups (52 of the 78 deaths $(67 \%)$ in those not followed up $v 88$ of the 129 deaths $(68 \%)$ in those followed up; $\chi^{2}=0.54, \mathrm{P}=0.817$ ). By the end of the study 135 patients had never had an outpatient cardiology review and 62 had had no further hospital contact.

Of the 488 patients alive at August 1998, 282 were recorded as having or not having angina. Ninety eight had documented ongoing anginal symptoms, of whom 45 required two or more antianginal drugs; none of the 21 patients under the care solely of their general practitioner but 20 of the 24 patients under specialist review were being investigated.

\section{Comment}

Survivors of myocardial infarction comprise a mixed group with varying degrees of underlying coronary disease, cardiac impairment, and socioeconomic status, all of which influence health care needs. ${ }^{3}$ The prospects for a patient surviving an infarction are not particularly 